\title{
Types of Foreign Body In Ear, Nose And Throat In Western Part Of Nepal
}

\author{
Rishi Bhatta ${ }^{1 *}$, Manita Pyakurel ${ }^{2}$ and Ramesh Parajuli ${ }^{1}$ \\ ${ }^{1}$ Department of ENT/HNS, Chitwan Medical College, Nepal \\ ${ }^{2}$ Department of Community Medicine, Nepalgunj Medical College, Nepal
}

Submission: February 22, 2017; Published: March 03, 2017

*Corresponding author: Rishi Bhatta, Asst Professor, Department of ENT/HNS, Nepalgunj Medical College, Nepal, Tel: 9841364427; Email: drrishient@gmail.com

\begin{abstract}
Introduction: Foreign body in ear, nose and throat though being a common entity needs specific technique and condition to remove.

Methods: A retrospective descriptive study was done in patients presenting in a tertiary referral center. Demography along with site, type of foreign body along with its removal was recorded in a proforma.

Results: Out of total 211 cases recorded, 118 were male and 93 female. Most of them were less than five years. Most of the presentation was in nose $(40.2 \%)$ followed by ear $(34.1 \%)$ and throat (24.1\%). Average duration of presentation in our hospital was 1.2 days with ten cases presenting after 1 week of insertion. Common foreign bodies in ear were grain seed (41.6\%), Plastic bead (20.8\%) and insect (13.8\%). Common foreign bodies in nose were eraser (35.2\%), Plastic bead (23.5\%) and grain seed (18.8\%). Throat foreign body comprises mainly coin (58.8\%) and bone (39.2\%). Removal was done in OPD setting in $87.5 \%$ of ear foreign body, and $96.4 \%$ of nasal foreign body. In case of throat foreign body, only $63.6 \%$ was removed in OPD setting and rest needed general anaesthesia for removal. All foreign bodies were removed within 24 hours of presentation in hospital.
\end{abstract}

Conclusion: Foreign bodies in ENT can be treated immediately without much morbidity and mortality if presented to an institution with otolaryngology services on time. Foreign bodies being more common in children warrants more watchfulness from family members.

Keywords: Ear; Foreign body; Nose; Throat

\section{Introduction}

Ear, nose and throat foreign bodies (FB) are common in otorhinolaryngological clinical practice. It is commonly seen in children who have habit of inserting nearby objects in their nose, ear or mouth. This can cause minor irritation to life threatening problem. Removal of FB requires good light, a cooperative or fully restrained patient and a gentle approach by the clinician. An accurate diagnosis of the FB should be made prior to attempts to remove it [1,2]. Increasing awareness of the prime health workers may be tried to reduce incidence of this risky health event. Capacity building of the primary level physicians to handle foreign body insertion cases can lessen the stress of the victim children and their parents [3].

Foreign body injuries constitute a significant portion of pediatric trauma in clinical practice. The under 3 years are most affected [3-5]. There is need for more public education of parents and care givers so as to prevent this avoidable injury $[3,4,6]$. In most of the studies, ear foreign body was most common $[4,5,7,8]$. While in others, nasal FB was more common [3]. There is past history of similar incidence in about one fourth of cases [3]. In such cases underlying morbidity like glue ear, otomycosis, ear wax, allergic rhinitis, teething etc should be ruled out.

The type of foreign bodies varies with age group and site of foreign body lodgment. In general, common foreign bodies in both adult and children are food related while small objects such as stone, plastic object and eraser in pediatric group [5-7]. FBs in the ear and nose were found more frequently in children, and the throat was the most common site of FB in adults and elderly people. Most of the FBs can be easily removed in emergency room or outpatient department $[8,9]$.

Sometime patient can present with FB in ear, nose and throat without history of insertion. In such case especially in children high degree of suspicion is required to diagnose. Correlation 
of symptomatology and demography with type of foreign body may be helpful for implementing preventives measures and better management of case. This study was designed to establish the local data of Otorhinolaryngological foreign bodies in term of prevalence among pediatric and adult groups, the clinical features, types of foreign body at different sites, and laterality of foreign bodies.

\section{Materials and Methodology}

A descriptive cross sectional study was carried out in Nepalgunj medical college at Nepalgunj, a referral center for midwestern and farwestern region of Nepal, from 1st Jan 2016 to 31st Dec 2016. Patients of all ages and sex presenting in outpatient department (OPD) and emergency departments with history of foreign body insertion or those who underwent FB removal were evaluated and case entered into proforma sheet. The cases were analyzed according to demography, nature and type of FB. Patient who didn't have FB presence during detail examination and relevant investigations or those who didn't allow removal in our hospital were excluded from study. Ethical approval was taken from Ethical committee. Comparison was done between types of FB and demography of patient. Data was Table 1: Different types of foreign bodies. analyzed using SPSS 17th version. Descriptive statistics was presented including mean, SD, frequency and percentage.

\section{Results}

There were 211 cases recorded, out of which 118 were male and 93 female. Commonest age group irrespective of type and site of foreign body was less than five years. It accounts $50.2 \%$ of total cases followed by $5-15$ years $(22.7 \%), 15-30$ years $(18.9 \%)$ and more than 30years (8.0\%). Most of the presentation was in nose $(40.2 \%)$ followed by ear (34.1\%) and throat $(24.1 \%)$. There were 3 recorded cases of foreign body in neck and face region.

All patients presented within a day to nearby center when they suspect foreign body insertion. Average duration of presentation in our hospital was 1.2 days. There were ten cases who presented after 1 week of insertion. Two of them couldn't come to hospital in time due to transportation difficulty while remaining eight were held in local health center with medication and alternative removal methods. Out of ten, only one was in throat while five were in nose and four in ear. There were past history of foreign body insertion in two patients. Both of them had nasal foreign body in past.

\begin{tabular}{|c|c|c|c|c|c|}
\hline Foreign body & Ear & Nose & Throat & Neck/Face & Total \\
\hline Grain seed & 30 & 16 & 0 & 0 & 46 \\
\hline Plastic bead & 15 & 20 & 0 & 0 & 35 \\
\hline Insect & 10 & 3 & 0 & 0 & 13 \\
\hline Cotton & 7 & 0 & 0 & 0 & 7 \\
\hline Stone & 3 & 8 & 0 & 0 & 11 \\
\hline Eraser & 3 & 30 & 0 & 0 & 33 \\
\hline Paper & 2 & 3 & 0 & 0 & 5 \\
\hline Metal & 2 & 5 & 30 & 2 & 39 \\
\hline Fish Bone & 0 & 0 & 8 & 0 & 8 \\
\hline $\begin{array}{l}\text { Chicken/Mutton } \\
\text { bone }\end{array}$ & 0 & 0 & 12 & 0 & 12 \\
\hline Veg twig/Thorn & 0 & 0 & 1 & 1 & 2 \\
\hline Total & 72 & 85 & 51 & 3 & 211 \\
\hline
\end{tabular}

Different types of foreign body in ear, nose and throat has been presented in (Table 1). Average age of foreign body insertion in ear was 3.5 years while that of nose was 2.8 years. Regarding throat it was 23.2 years. Right ear $(62.5 \%)$ and left nostril ((56.4\%) were common sides. Common foreign bodies in ear were grain seed (41.6\%), Plastic bead (20.8\%) and insect (13.8\%). Common foreign bodies in nose were eraser $(35.2 \%)$, Plastic bead $(23.5 \%)$ and grain seed $(18.8 \%)$. Throat foreign body comprises mainly coin $(58.8 \%)$ and bone $(39.2 \%)$. There were 2 cases with foreign body in neck which were accidental insertion of metallic pin. There was a case of thorn insertion in face presenting as discharging sinus.
Few people were not aware of foreign body inserted in their body. There were various ways of presenting such cases as depicted in (Table 2). Nasal discharge or ear discharges were common presentations when patients were not aware of it. Removal was done in OPD setting in $87.5 \%$ of ear foreign body, and $96.4 \%$ of nasal foreign body. In case of throat foreign body, only $63.6 \%$ was removed in OPD setting and rest needed general anaesthesia for removal. Regarding neck and face foreign body exploration was done in general anaesthesia. All foreign bodies were removed within 24 hours of presentation in hospital. 
Table 2: Common presentations of foreign bodies in ENT.

\begin{tabular}{|c|c|c|c|c|c|}
\hline \multicolumn{2}{|c|}{ Ear } & \multicolumn{2}{|c|}{ Nose } & \multicolumn{2}{|c|}{ Throat } \\
\hline Complaints & Number & Complaints & Number & Complaints & Number \\
\hline $\begin{array}{l}\text { Foreign body } \\
\text { inserted }\end{array}$ & 60 & $\begin{array}{l}\text { Foreign body } \\
\quad \text { inserted }\end{array}$ & 51 & $\begin{array}{l}\text { Foreign body } \\
\text { inserted }\end{array}$ & 44 \\
\hline Ear discharge & 12 & Nasal discharge & 24 & $\begin{array}{l}\text { Pain and } \\
\text { discomfort }\end{array}$ & 51 \\
\hline Pain in ear & 10 & Pain in nose & 7 & & \\
\hline $\begin{array}{c}\text { Mass/object in ear } \\
\text { canal }\end{array}$ & 2 & Mass in nose & 7 & & \\
\hline
\end{tabular}

\section{Discussion}

Foreign bodies are emergency ENT condition [10,11]. If not attended at time it can lead to hazardous complications [11]. Around $94 \%$ cases presented immediately on suspecting foreign body insertion and they got it removed within 24 hours of presentation as in Malaysian study [1]. It is the concern regarding remaining $6 \%$ cases that were held unnecessary in a center, where it couldn't be removed. It indicates necessity to educate local health professional for better management [7]. Although there might have been lot more cases where FB was removed by primary health professionals and who need not have to reach our center; but we need to decrease those cases who suffered unnecessarily due to improper guidance.

Foreign bodies in the aero digestive tract tend to present earlier as it cause extreme discomfort [1]. There was a significantly higher proportion of foreign body in the right ear as in Hon study [1] but contrasting in case of nose. Mean age was 5.7 years in this study which was comparable to most of the studies $[3,6,9]$ but lower as compared to Shrestha study (21.2years) [2] ; while male predominance was seen in all these studies. Children being inquisitive of their body part may be exploring and putting things in their orifice. Foreign body of the ear was found to be most frequent in some studies [2,8,9] but in our study it was more common in nose as in Mukherjee study [3] and Ibekwe study [6].

The increased risk of FB aspiration in children is due to the different structure of the pharynx and the upper airways compared to adults. In addition, children have an immature swallowing mechanism and they most commonly aspirate food stuffs. FB aspiration is usually a sudden and dramatic event when the child feels that he is suffocating or choking [12]. There were just 3 cases of FB bronchus presented in our hospital; which couldn't be removed due to lack of proper instruments. All three of them were immediately referred to nearby branch of same hospital, where timely intervention saved their lives.

Past history was found in only 2 cases which was lower as compared to Mukherjee study [3] but nasal foreign body was predominant in both study. Although there was no psychiatric condition in our two cases, but it is advisable to rule out in patients with repeated foreign body insertion. In contrast to study done in Melanesian children [4] where ear foreign body was commonest, we found nasal foreign body to be more common. This difference may be culturally, socially directed and availability of local substance. In our study commonest foreign body overall is grain seed (21.8\%) followed by metal (18.4\%) and plastic bead(16.5\%).Although seed and plastic bead were common in Melanesian children [4] study also, but stone which was common in that study was not in ours.

Nasal foreign bodies are frequently encountered in the emergency setting of ear, nose, and throat diseases. Although they are not life-threatening conditions, they require urgent intervention, as they may lead to several complications in the long-term. Parents and caregivers of children should keep objects which can be put into the nose away and be instructed that they should consult a physician in case of nasal foreign bodies $[13,14]$. There was a strong correlation between duration of FB insertion and associated complications [15]. Repeated failed attempts and delayed referrals to Otorhinolaryngologists from peripheral centers were also contributing factors to increased morbidity and hence the need for awareness $[15,16]$. Although there were no complications in our center during study period, but we need to take necessary steps to avoid such occurrence.

\section{Conclusion}

Foreign bodies in ENT can be treated immediately without much morbidity and mortality if presented to an institution with Otolaryngology services on time. Foreign bodies being more common in children warrants more watchfulness from family members and one need to rule out FB in unilateral undefined presentation in ear and nose.

\section{References}

1. Hon SK, Izam TM, Koay CB, Razi A (2001) A prospective evaluation of foreign bodies presenting to the Ear, Nose and Throat Clinic, Hospital Kuala Lumpur. Med J Malaysia 56(4): 463-470. 
2. Shrestha I, Shrestha BL, Amatya RC (2012) Analysis of ear, nose and throat foreign bodies in dhulikhel hospital. Kathmandu Univ Med J (KUMJ) 10(38): 4-8.

3. Mukherjee A, Haldar D, Dutta S, Dutta M, Saha J, Sinha R (2011) Ear, nose and throat foreign bodies in children: a search for socio-demographic correlates. Int J Pediatr Otorhinolaryngol 75(4): 510-512.

4. Endican S, Garap JP, Dubey SP (2006) Ear, nose and throat foreign bodies in Melanesian children: an analysis of 1037 cases. Int J Pediatr Otorhinolaryngol 70(9): 1539-1545

5. Pecorari G, Tavormina P, Riva G, Landolfo V, Raimondo L, et al. (2014) Ear, nose and throat foreign bodies: the experience of the Pediatric Hospital of Turin. J Paediatr Child Health 50(12): 978-984.

6. Ibekwe MU, Onotai LO, Otaigbe B (2012) Foreign body in the ear, nose and throat in children: A five year review in Niger delta. Afr J Paediatr Surg 9(1): 3-7.

7. Kumar S (2004) Management of foreign bodies in the ear, nose and throat. Emerg Med Australas 16(1): 17-20.

8. Chiun KC, Tang IP, Tan TY, Jong DE (2012) Review of ear, nose and throat foreign bodies in Sarawak General Hospital. A five year experience. Med J Malaysia 67(1): 17-20.

9. Parajuli R (2015) Foreign bodies in the ear, nose and throat: an experience in a tertiary care hospital in central Nepal. Int Arch Otorhinolaryngol 19(2): 121-123.

10. Ray R, Dutta M, Mukherjee M, Gayen GC (2014) Foreign body in ear nose and throat: experience in a tertiary hospital. Indian J Otolaryngol Head Neck Surg 66(1):13-16.

11. Ghosh P (1999) Foreign bodies in ear, nose and throat (Predictions and management). Indian J Otolaryngol Head Neck Surg 51(Suppl 1): 2-5.

12. Cohen S, Goldberg S, Springer C, Avital A, Picard E (2015) Foreign body aspiration in children. Harefuah 154(3): 175-177.

13. Memiș M, İlhan E, Ulucanlı S, Yaman H, Güçlü E (2015) Nasal foreign bodies: an analysis of 130 patients. Kulak Burun Bogaz Ihtis Derg 25(2):109-112.

14. Yaroko AA, Baharudin A (2015) Patterns of nasal foreign body in northeast Malaysia: A five-year experience. Eur Ann Otorhinolaryngol Head Neck Dis 132(5):257-259.

15. Oreh AC, Folorunsho D, Ibekwe TS (2015) Actualities of management of aural, nasal, and throat foreign bodies. Ann Med Health Sci Res 5(2): 108-114.

16. Al-Juboori AN (2013) Aural foreign bodies: descriptive study of 224 patients in Al-fallujah general hospital, iraq. Int J Otolaryngol 2013 401289.

\section{Your next submission with Juniper Publishers} will reach you the below assets

- Quality Editorial service

- Swift Peer Review

- Reprints availability

- E-prints Service

- Manuscript Podcast for convenient understanding

- Global attainment for your research

- Manuscript accessibility in different formats

( Pdf, E-pub, Full Text, Audio)

- Unceasing customer service

Track the below URL for one-step submission https://juniperpublishers.com/online-submission.php 